\title{
Milwaukee Psikoterapi Beklentileri Ölçeğinin Türkçeye Uyarlanması: Geçerlik ve Güvenirlik Çalışması
}

DOI: 10.26466/opus.595768

$*$

Kerem Çetinkaya* - Çiğdem Yavuz Güler**

* Öğr. Görevlisi, Milli Savunma Üniversitesi, Deniz Harp Okulu, Tuzla / İstanbul / Türkiye E-Posta: keremcet01@gmail.com

ORCID: 0000-0002-0612-3541

** Dr. Öğr. Üyesi, Üsküdar Üniversitesi, İnsan ve Toplum Bilimleri Fakültesi, Üsküdar / İstanbul E-Posta: cigdemyavuzguler@gmail.com

ORCID: 0000-0001-7996-0984

Öz

Bu çalışmanın amacı Norberg, Wetterneck, Sass ve Kanter (2011) tarafindan geliştirilen Milwaukee Psikoterapi Beklentiler Ölçeği (MPBÖ)'nin Türk kültürü için geçerlik güvenirliğini incelemektir. Araştırmaya yetişkin bireylerden oluşan 328 kişi (248 kadın, 80 erkek) katılmıştır. Ölçeğin yapı geçerliği doğrulayıcı faktör analizi ile sinanmıştır. Uyum geçerliğini sınamak amacıyla Psikolojik Yardım Almaya İlişkin Tutum Ölçeği-Kısa Formu (PYAİTÖ-KF) ve Psikoterapi Hakkında Düşünceler Ölçeği (PHDÖ) ile korelasyonlarına bakılmıştır. Ölçeğin güvenirliği ise iç tutarlılık ve test tekrar test yöntemleriyle hesaplanmıştır. Yapılan faktör analizi sonucunda MPBÖ, orjinal formuna benzer şekilde süreç beklentileri ve sonuç beklentileri olmak üzere iki faktörlü bir yapı ortaya çıkmıştır. Ölçeğin süreç beklentileri ve sonuç beklentileri alt boyutlarının, Psikolojik Yardım Almaya İlişkin Tutum Ölçeği ile pozitif ve Psikoterapi Hakkındaki Düşünceler Ölçeği alt boyutlarıyla negative yönde ilişkili olduğu saptanmıştır. Ölçeğin süreç alt boyutu iç tutarlılık kat sayısı .84, test tekrar test güvenirlik katsayısı .82 , sonuç alt boyutu iç tutarllık kat sayısı .88, test tekrar test güvenirlik katsayısı ise .76 olarak bulunmuştur. MPBÖ'nün Türk kültüründe bireylerin psikoterapi beklentilerini ölçebilmek amactyla kullanılabilecek geçerli ve güvenilir bir araç olduğu belirlenmiştir.

Anahtar Kelimeler: Psikoterapi, Psikoterapi beklentileri, Geçerlik, Güvenirlik 


\title{
Adaptation of Milwaukee Psychotherapy Expectations Scale into Turkish: Validity and Reliability Study
}

\begin{abstract}
The aim of this study is to examine psychometric properties of the Turkish version of the Milwaukee Psychotherapy Expectations Questionnaire (MPEQ). 328 adult individuals (248 females, 80 males) participated in the study. The construct validity of the scale was tested by confirmatory factor analysis. In order to test the convergent validity, the correlations with Attitudes Toward Seeking Professional Psychological Help and Thoughts About Psychotherapy were examined. The reliability of the scale was calculated by internal consistency and test-retest methods. As a result of the factor analysis, MPEQ was formed a two-factor structure, namely, process expectations and outcome expectations similar to the original scale. The process and outcome expectations subscale were found to be positively correlated with Toward Seeking Professional Psychological Help Scale and negatively correlated with Thougts About Psychotherapy Survey. The internal consistency coefficient of the process subscale of the scale was .84, and the test-retest reliability coefficient was .82. The internal subscale coefficient of the scale was .88 and the test-retest reliability coefficient was.76. It was determined that MPEQ is a valid and reliable tool that can be used to measure the psychotherapy expectations of Turkish individuals.
\end{abstract}

Keywords: Psychotherapy, Psychotherapy expectations, Validity, Reliability 


\section{Giriş}

Psikoterapi araştırmaları, psikoterapiye yönelik olarak danışanların beklentilerinin tedavi sürecinde önemli olduğunu göstermektedir. (Constantino, 2012; Frank, 1968, 1973; Goldstein, 1962; Goldstein ve Shipman, 1961; Gonzalez, Tinsley ve Kreuder, 2002; Grencavage ve Norcross, 1990; Rosenthal ve Frank, 1956). Araştırmacılar, danışanların beklentilerinin psikoterapiye başlamaya, psikoterapinin sürecine ve sonucuna etki ettiğini belirtmektedirler (Volpe, 2014). İnsanlar psikoterapiye nasıl ve ne kadar yardım alabileceği yönünde bir takım beklentilerle gelmektedirler (Frank, 1968; Goldstein, Heller ve Sechrest, 1966; Greenberg, Constantino ve Bruce, 2006; Norberg, Wetterneck, Sass ve Kanter, 2011; Tinsley ve Harris, 1976). Bu beklentiler, kişinin psikoterapiye başlaması, süreç içerisinde kendisiyle ilgili özel bilgileri paylaşmaya yönelik istekli olması gibi danışma sürecinde danışanın davranışlarını etkileyen önemli faktörlerdir (Tinsley, Workman ve Kass, 1980). Bu araştırmalar; beklentilerin, psikoterapi sürecini, süreç içerisinde psikoterapi müdahalesini, danışanın davranışlarını ve terapinin verimliliğini etkilediğini göstermektedir.

Psikoterapiye ihtiyaç duyan fakat yardım almayan bireylerin, terapinin hoş bir şey olmadığı veya işe yaramadığı yönünde inançları olabilir (Tinsley ve Harris, 1976). Psikoterapiye hiç başlamayanların yanı sıra psikoterapiye başlayan tüm danışanların yarısı psikoterapiyi bırakmaktadırlar (Wierzbicki ve Pekarik, 1993). Psikoterapinin etkili ve yararlı olmadığ 1 inancında olan bireylerin, daha önce psikoterapi deneyimi varsa bu kişilerin eski deneyimlerinde beklentilerinin yeterli düzeyde karşılanmadığı düşünülebilir. Buna benzer şekilde psikoterapiye başlayıp da yarıda bırakan danışanların, bıraktıkları süreye kadar olan kısımda, terapiden beklediklerini alamadıkları da düşünülebilir. Garfield (1994), danışanların psikoterapi öncesindeki terapi beklentilerinin karşılanmamasının, danışanların terapiden memnun kalmamasına neden olduğunu ifade etmektedir. Aynı nedenin danışanların terapiyi yarıda bırakmasına da yol açtığı belirtilmektedir. Bu gibi nedenlerle danışanların terapiye başlarken ya da daha başlamadan önce psikoterapiyle ilgili beklentilerinin belirlenebilmesi, bireyin terapi yardımını almasını veya terapi yardımından daha fazda faydalanmasını sağlayabilir. Terapilerin ilk görüşmel- 
erinde neredeyse bütün terapi ekolleri tarafından sorulan, "Terapi sürecinden beklentileriniz nelerdir?" sorusu danışanların beklentilerinin belirlenmesine yönelik bir sorudur. Bu soruyla danışan terapinin etkililiğine yönelik inançlarını, terapiye güvenini ve beklentilerini dile getirmektedir. Terapist, bu soru ışığında terapi sürecini biçimlendirebilir, bu soruyu dikkate almaz ise danışanın beklentileri ve inançları doğrultusunda ilerlemediği için terapinin ilerde sorunlu bir sürece doğru sürüklenmesine neden olabilir.

Çeşitli araştırmalar danışanların beklentilerinin psikoterapi sürecine etkisi olduğunu ortaya koymuştur (Arnkoff, Glass ve Shapiro, 2002; Connolly vd., 2003; Frank, 1968; Goldstein, 1962; Lennard ve Bernstein, 1960; Miller, 2009). Terapinin başlangıcında danışanların beklentilerini yönetmek, danışanları terapötik sürece dahil etmedeki ilk sorunları aşmanın önemli bir yoludur (Ekberg, Barnes, Kessler, Malpass ve Shaw, 2014). Danışanların beklentileri hakkında bilgi sahibi olmak, onların yaşantılarını anlamada ve terapi sürecini planlamada yararlı olmaktadır, ayrıca terapiyle ilgili net beklentilere sahip danışanların sürece devam etme konusunda daha istekli oldukları gözlenmektedir (Tambling, Wong ve Anderson, 2014). Bu nedenle terapistler, danışanların beklentilerini anlayabilmek ve cevaplayabilmek için hazırlıklı olmalıdırlar. Bazı araştırmacılar, terapötik iyileşmenin \% 15'ini hastanın beklentilerinin etkilerine bağlamaktadırlar. (Lambert ve Barley, 2001). Yani terapi sürecine başlayan bir danışan, psikoterapiye yönelik olumlu beklentilere sahipse terapi sürecinden faydalanma oranı o kadar kolay olabilecektir. Bunun tam tersi şekilde olumsuz beklentileri olan yani etkililiğine çok fazla inanmayan bir kişini süreçten faydalanması o kadar zor olacaktır. Bu noktada olumsuz beklentilere sahip olan danışanlarla yapılması gereken çalışmaların başında bu beklentilerin yer alması süreç için olumlu olacaktır.

Beklenti kavramı, araştırmaların ve psikolojinin odak kavramlarından biri olmuştur (Tinsley, Bowman ve Barich, 1993). Araştırmacılar, danışanların beklentilerini, terapi sürecinin ve sonucunun etkili bir unsuru olarak görmektelerdi (Tinsley, Brown, Aubin, ve Lucek, 1984). Yapılan bazı araştırmalar, beklentilerin bir kişinin terapiye başlama yönündeki ilk kararını etkilediğini ve bireylerin yardım almaya karar vermesinin ardından, terapiye bu beklentilerle geldiklerini göstermektedir (Tinsley vd., 
1984). Araştırmaların bulguları, danışanların ilk görüşmeden sonra tedaviyi bırakma kararlarının kısmen, terapi beklentilerini ve terapide nelerin gerçekleşebileceği arasındaki tutarsızlıktan kaynaklanabileceğini ortaya koymuştur (Heilbrun, 1970; Sandler, 1975). Bu nedenle, beklentiler sadece terapi süreci ve sonucunda değil, aynı zamanda terapiye girme ve terapide kalmaya devam eden bir kişinin ilk kararının da önemli aracıları olarak tanımlanmaktadır. Farklı araştırmacılar farklı beklenti boyutları tasarlamışlardır (Berzins, 1971). Terapi beklentisi, literatürde genel olarak tedavi beklentileri ve sonuç beklentileri şeklinde açıklanmaktadır (Tinsley, Holt, Hinson ve Tinsley, 1991). Bu çalışmada da beklentiler, sonuç beklentileri ve tedavi beklentileri şeklinde açıklanmaktadır.

\section{Sonuç Beklentileri}

Danışanların sürecin sonucunda neler olacağı ve nasıl sonlanacağı ile ilgili beklentilerini içermektedir. Sonuç beklentisi; "Verilen terapi ya da tedavinin bana ne kadar yardımcı olacağına inanıyorum?" sorusunu sormaktır (Constantino, Ametrano ve Greenberg, 2012). Bu beklenti ile ilgili olarak Frank (1961) sonuç ile ilgili olumlu ve umutlu beklentilerin terapinin etkililiğine olumlu bir etki ettiğinden bahsetmektedir.

Danışanların terapi sonuç beklentileri ile ilgili üç olası tip vardır (Glass, Arnkoff ve Shapiro, 2001). İlk tipteki danışanlar, terapinin kendilerine yardımcı olacağı konusunda olumlu bir beklentiye sahip olanlardır. Bu beklentiler, terapinin danışana iyi geleceği inancını göstermektedir ve bu danışanlar terapiden memnun kalacaklardır. İkinci tipteki danışanlar, terapi ile ilgili kararsız ve belirsiz hissedenlerin olduğu gruptur. Terapinin kendilerine yardımcı olup olmayacağı konusunda ikilemde kalmaktadırlar. Bu ikilemli beklentiler, danışanların terapinin faydası hakkında değişken duygular yaşamaktadırlar. Son tipte olumsuz beklentiye sahip danışanlar mevcuttur. Bu danışanlar, terapinin kendilerine fayda sağlamayacağını düşünmektedirler. Bu tür bir beklenti, terapinin yararlılığına yönelik güven eksikliğini ifade etmektedir. 


\section{Tedavi Beklentileri}

Tedavi beklentileri, danışanların terapi uygulaması ile ilgili ne gibi beklentilere sahip olduğunu ifade etmektedir. Bu beklenti türü, (a) rol beklentileri ve (b) süreç beklentileri şeklinde ayrıca sınıflandırılmaktadır.Rol beklentileri, belirli bir pozisyonda bir kişinin beklediği davranışa atıfta bulunmaktadir (Constantino, Glass, Arnkoff, Ametrano ve Smith, 2011). Başka bir deyişle, rol beklentileri, hem danışan hem de terapist davranışları hakkındaki düşünceleri içermektedir. Rol beklentilerinin bazı örnekleri, terapistten tavsiye vermesine veya terapistle işbirliğine dayalı bir ilişki beklemek şeklindedir (Dew ve Bickman, 2005). Bu beklenti türü direkt olarak terapi uygulamasının kendisi ile ilgilidir.

Süreç beklentileri, terapötik süreç hakkındaki beklentiler, tedavi süresi ve kullanılan terapötik teknikler gibi tedavi yönleriyle ilgili öznel danışan beklentilerini içerir (Constantino vd., 2012). Bu beklentiler, büyük oranda, danışanın başlayacağı terapi yaklaşımının nasıl bir süreci olduğu ile ilgili beklentileri kapsar. Constantino vd. (2011), belirli tedavi beklentileri türleri olarak, rol ve süreç beklentileri arasında genellikle net bir ayrım bulunmadığ 1 konusunu belirtmektedir.

Bu çalışmada psikolojik yardım alma sürecinde oldukça önemli olan, psikoterapi beklentileri ile ilgili bilgi toplamayı sağlayan Norberg vd. (2011) tarafından geliştirilen Milwaukee Psychotherapy Expectations Questionnaire (MPEQ) isimli ölçme aracının Türkçe 'ye uyarlaması ve psikometrik özelliklerinin incelenmesi amaçlanmıştır.

\section{Yöntem}

\section{Çalışma Grubu}

Milwaukee Psikoterapi Beklentileri Ölçeği'nin geçerlik ve güvenirlik çalışmaları yapılırken katılımcıların tamamı orijinal çalışmada olduğu gibi yetişkin bireylerden seçilmiştir. Çalışmanın katılımcı grubunu 248'i (\%75.6) kadın ve 80'i (\%24.4) erkek olmak üzere toplam 328 birey oluşturmaktadır. Yaşları 20 ile 64 arasında değişmekte olan katılımcıların yaş ortalaması 28.34'tür (ss $=7.67)$. 


\section{Veri Toplama Araçları}

Araştırmada veri toplamak amacıyla MPBÖ’nün yanı sıra, ölçüt geçerliliğini sınamak amacıyla Psikolojik Yardım Almaya İlişkin Tutum Ölçeği-Kısa Formu (PYAİTÖ-KF) ve Psikoterapi Hakkında Düşünceler Ölçeği (PHDÖ) de kullanılmıştır.

Milwaukee Psychotherapy Expectations Questionnaire (MPEQ): Milwaukee Psikoterapi Beklentiler Ölçeği (Milwaukee Psychotherapy Expectations Questionnaire - MPEQ) Norberg vd. (2011) tarafından geliştirilen, bireylerin psikoterapiye yönelik beklentilerini ölçen bir veri toplama aracıdır. MPBÖ den önce geliştirilmiş olan ölçeklerden Psychotherapy Expectancy Inventory-Revised (PEI-R) 'nin yalnızca tedavi (sonuç) beklentilerine odaklanmas1, Expectations About Counseling Scale (EAC)'nin 66 maddelik ve 135 maddelik olan formların çok uzun olması nedeniyle kullanışsız olması araştırmacıyı yeni bir ölçek geliştirmeye itmiştir. Nornberg vd. (2011) MPBÖ’nün maddelerini, daha önce geliştirilen ölçeklerin kuramsal alt yapılarına dayanılarak belirlemiş ve ölçeğin ilk hali 28 madde olarak tasarlamıştır. Ölçeği geliştirme sürecinde dört farklı uygulama gerçekleştirmiştir. İlk uygulama açımlayıcı faktör analizi uygulamasıdır. Bu uygulamada ölçek, psikoloji bölümünde okuyan 599 üniversite öğrencisine uygulanmıştır. Bu uygulamanın sonucunda 3 faktörlü bir yapı bulunmuş fakat uyum indeksinin zayıf olduğu görülmüştür. Madde yüklerine bakıldığında 15 maddenin beklenen değerleri karşılamadığ için çıkarılmasına karar verilmiştir. Böylelikle ölçek 13 maddelik son halini almıştır. Bu 13 maddenin her birinin madde yükü .30 ‘dan yüksek bulunmuştur. İkinci uygulamada doğrulayıcı faktör analizini kullanarak ölçeği test etmek amaçlanmaktadır. Aynı zamanda iç tutarlılık ve tekrar test ile geçerliliğin sınanması amaçlanmaktadır. Bu uygulamada 180 üniversite öğrencisine, yedi gün aralıkla MPBÖ iki kez uygulanmıştır. Yapılan analiz, bir modelde karşılaştırılabilir model uyum istatistiklerini ortaya çıarmaktadır $(\div 2 / \mathrm{df}=4.62, \mathrm{RMSEA}=.13, \mathrm{CFI}=.95, \mathrm{TLI}=.94, p<.001)$ ve zaman iki $(\div 2 / d f=3.33$, RMSEA $=.11)$ CFI $=.96$, TLI $=.96, p<.001)$. Alfa katsayılarının analizi 0.86 'dan 0.91'e kadar olan katsayılı á ile iyi iç tutarlllık göstermiştir. Bir haftalık test-tekrar test güvenilirliği tedavi beklentileri için $r=0.83$ olan korelasyon katsayıları ve sonuç beklentileri için $r=$ 
0.76 bulunmuştur (Nornberg vd., 2011). Üçüncü çalışmada ölçek 302 üniversite öğrencisine uygulanmıştır. Bu uygulama ile MPBÖ’ nün iki faktörlü yapısını doğrulamak için gerçekleştirilmiştir. Doğrulayıc faktör analizi, bu örneklemin önceki çalışmalara benzer model uyum istatistikleri olduğunu ortaya koymuştur $(\chi 2 / \mathrm{df}=7.33, \mathrm{RMSEA}=.15, \mathrm{CFI}=.95, \mathrm{TLI}=$ $.94, p<.001$ ). Alfa katsayılarının analizi, 0.90 ile 0.91 arasında değişen $\alpha$ katsayısı ile iyi bir iç tutarlılığa sahip olduğunu göstermiştir. Dördüncü çalışmada MPBÖ' nün tahmini geçerliliğini değerlendirmek için yapılmıştır (Nornberg vd., 2011). Bu çalışmadaki örneklemi bir üniversitenin klinik psikoloji eğitim merkezinde hizmet alan 78 danışan oluşturmaktadır. Doğrulayıc faktör analizi, MPBÖ' nün öğrencilerin yerine bir klinik örnek kullanarak faktör yapısını incelemek ve ayrıca MPBÖ' nün bir tedavi seansına katılımı öngörmede kullanılıp kullanılamayacağını belirlemek için kullanılmıştır. Sonuç olarak önceki çalışmalara benzer model uyum verilerine ulaşılmıştır. $(\chi 2 / d f=2.17$, RMSEA $=.12$, CFI $=.94, \mathrm{TLI}=.93, p<.001)$. Sonuç olarak MPBÖ, bireylerin psikoterapiye yönelik beklentilerini ölçen, 13 maddeden oluşan, süreç beklentileri ve sonuç beklentileri şeklinde iki boyuttan oluşan, 0 (Hiç Değil) ile 10 (Çok Fazla) arasında değerlendirilen, geçerliği ve güvenirliği kanıtlanmış bir veri toplama aracı olarak belirtilmiştir.

\section{Psikolojik Yardım Almaya İlişkin Tutum Ölçeği-Kısa Form (PYAİTÖ-} KF): Profesyonel Psikolojik Yardım Almaya Yönelik Tutum Ölçeği - Kısa Form'u (Attitudes Toward Seeking Professional Psychological Help Scale - Short Form), Fischer ve Turner (1970) tarafından geliştirilen ölçeğin, Fischer ve Farina (1995) tarafından kısaltılan tek faktörlü bir yapı ve 10 maddeye sahip olan halidir. Ölçeğin Cronbach alfa iç tutarlık katsayısı .84 ve test-tekrar test güvenirliği .80 olarak belirtilmiştir. PYAİTÖ-KF, 4'lü Likert tipi bir ölçme aracı olup, ölçekten en düşük 0 en fazla 30 puan alınabilmektedir. Ölçekten alınan yüksek puanlar, bireyin psikolojik yardım almaya yönelik olumlu tutumlarının yüksekliğine işaret etmektedir. Türkçe'ye uyarlama çalışması Topkaya (2011) tarafından yapılan ölçeğin Türkçe Formu dokuz maddeden oluşmakta ve tek faktörlü bir yap1 göstermektedir. Ölçeğin Türkçe Formu'nun iç tutarlılık katsayısı .76 olarak bulunmuştur. 
Psikoterapi Hakkındaki Düşünceler Ölçeği (PHDÖ): PHDÖ (Thoughts About Psychotherapy Survey); bireylerin psikolojik destek almaya ilişkin yaşadıkları korkuları ölçmek amacıyla geliştirilmiş bir veri toplama aracıdır (Kushner ve Sher, 1989). PHDÖ üç alt boyuta ve 19 maddeye sahiptir. Bu alt boyutlar, terapistin tepkisi, imaj sorunu ve zorlanma sorunudur. Ölçeğin orjinalinin alt boyutlarına ait Cronbach Alfa iç tutarlılık katsayıları sırasıyla $.92, .87$ ve .88 olarak belirlenmiştir (Kushner ve Sher, 1989). PHDÖ 'nün Türkçe 'ye uyarlama çalışması Topkaya (2011) tarafından yapılmıştır. Ölçeğin tüm alt boyutlarını kapsayan ölçüm modelinin kabul edilebilir uyum değerlerine sahip olduğu belirlenmiş ve PHDÖ 'nün tüm maddelerinin faktör yükleri anlamlı bulunmuştur. Ölçeğin bütünü için Cronbach Alfa iç tutarlılık katsayısı .91, madde toplam test korelasyonlarının .37 ile .65 arasında olduğu belirtilmiştir. Öte yandan ölçeğin terapistin tepkisi, imaj sorunu ve zorlanma sorunu alt ölçekleri için Cronbach Alfa içtutarlılık katsayısı sırasıyla .85, .79 ve .85 olarak hesaplanmıştır.

\section{Işslem}

MPBÖ 'nün uyarlama sürecinde, ölçme aracının geliştiricisine ulaşılarak, ölçeğin Türkçe'ye uyarlama çalışmasını yapabilmek için izin alınmıştır. Uyarlama çalışması için izin alındıktan sonra, ölçeğin Türkçe formunu hazırlamak için, orijinal ölçeğin Türkçe 'ye çevirisi yapılmıştır. Çeviri sürecinde için Sousa ve Rojjanasrirat'ın (2010) öngördüğü adımlar izlenmiştir.

1. Adım: Orjinal ölçeğin Türkçeye çevirilmesi ( tek yönlü çeviri).

2. Adım: Ölçeğin çevrilmiş hali ile özgün halinin karşılaştırılması.

3. Adım: İlk çevrilmiş halinin orjinal dile tekrardan çevrilmesi (geri çeviri).

4. Adım: Ölçeğin geriye çevrilmiş hali ile özgün halinin karşılaştırılmasi.

5. Adım: Ölçeğin Türkçeye çevirilen son halinin pilot uygulama çalışmasının yapılması neticesinde ölçeğin son halinin verilmesi.

Çeviri süreci yukarıda belirtilen doğrultuda, bir çeviri ekibi tarafından gerçekleştirilmiştir. Çeviri ekibi, ölçeği İngilizce 'den Türkçe 'ye çevirecek 3 kişi, Türkçe 'den İngilizce 'ye çevirecek 3 kişi ve her iki çeviriyi 
karşılaştırıp ölçeğin son halini oluşturan, araştırmacıların da dahil olduğu 3 kişi olmak üzere 9 kişiden oluşmaktadır. Elde edilen üç farklı çeviri, Psikoloji alanında Öğretim Görevlisi olan bir uzmanın ve araştırmacıların da dahil olduğu değerlendirme ekibi tarafından değerlendirilmiştir. Değerlendirme sonunda ölçeğin Türkçe formu oluşturulmuştur. Türkçe form, her iki dile de hakim olan Psikoloji alanından üç farklı uzman tarafından, Türkçeden İngilizceye çevrilmiştir. Türkçe'den İngilizce diline çeviriler ile orjinal ölçek karşuılaştırılmış ve değerlendirmeler sonucunda ölçeklerin Türkçe formu hazırlanmıştır. Hazırlanan formlar, 10 katılımcıya uygulanarak, ön uygulama ile denenmiş ve katılımcilardan alınan geri bildirimlerle son düzenlemeler yapılarak ölçeğin uygulamaya sunulan son hali oluşturulmuştur.

Ölçme araçları öncelikle 248 kişiye uygulanmış, sonrasında ölçeklerin tekrar test güvenirliğini değerlendirmek için, aynı sınıfta eğitime devam eden üniversite öğrencilerinden oluşan bir gruba ölçekler uygulanmış; tekrar test uygulamasının ikinci kısmı 2 hafta sonra, aynı gruba haftanın aynı gününde gerçekleştirilmiştir. İlk uygulamadaki gibi katılımcılara uygulama formu verilerek veriler toplanmıştır.

Ölçeğin Türkiye örnekleminde psikometrik özelliklerini değerlendirebilmek amacıyla yapı ve uyum geçerlikleri test edilmiştir. Bu bağlamda ölçeğin yapı geçerliğini değerlendirmek için doğrulayıcı faktör analizi ve uyum geçerliğini değerlendirebilmek için ise literatürde bulunan Türk kültüründe geçerliği ve güvenirliği kanıtlanmış ölçeklerle ilişkileri ele alınmıştır.

Ölçeğin güvenirliklerini sınamak amacıyla Cronbach alpha ve testtekrar test güvenirlik katsayıları ile madde analizleri ele alınmıştır. Testtekrar test güvenirliği için ölçekler iki hafta arayla 57 katılımcıya uygulanmış ve iki uygulama arasındaki ilişki hesaplanmıştır. Madde analizi bağlamında da madde-toplam korelasyon katsayıları incelenmiştir.

\section{Bulgular}

\section{Geçerlik}

Yapı Geçerliği:Milwaukee Psikoterapi Beklentileri Ölçeği'nin (MPBÖ) yapı geçerliğini sınamak amacıyla doğrulayıcı faktör analizi (DFA) 
gerçekleştirilmiştir. Daha önce belirtilen kriterler göz önüne alınarak gerçekleştirilen DFA'nın ilk sonuçlarına göre Milwaukee Psikoterapi Beklentileri Ölçeği'nin uyum iyiliği indekslerinin $[\chi 2(64, \mathrm{~N}=328)=$ $456.312, \chi 2 / s d=7.13 ; \mathrm{GFI}=.82 ; \mathrm{CFI}=.80 ; \mathrm{IFI}=.80 ; \mathrm{SRMR}=.083 ; \mathrm{RMSEA}=$ .137] olduğu görülmüş ve tüm indekslerinin kritik değerin altında olduğu anlaşılmıştır. Bununla birlikte, süreç boyutunun 1 ve 2 nolu, 3 ve 4 nolu ile 3 ve 7 nolu maddeleri arasında modifikasyon indekslerinin oldukça yüksek olduğu görülmüştür. Bu bağlamda bu maddeler arasında modifakasyon yapılarak DFA yenilenmiştir. DFA'ya yönelik sonuçlar Şekil 1'de yer almaktadir.

Şekil 1'den de görüleceği üzere süreç beklentileri boyutunda standardize edilmiş faktör yüklerinin .48 ile .74 arasında değiştiği ve tüm faktör yüklerinin anlamlı olduğu anlaşılmaktadır. Benzer şekilde sonuç beklentileri boyutunda da standardize edilmiş faktör yüklerinin .74 ile .87 arasında değiştiği ve tüm faktör yüklerinin anlamlı olduğu belirlenmiştir.

Ölçeğin uyum iyiliği indekslerinin $[\chi 2(61, \mathrm{~N}=328)=249.315, \chi 2 / \mathrm{s} d=$ 4.08; GFI $=.90 ; \mathrm{CFI}=.90 ; \mathrm{IFI}=.91 ; \mathrm{SRMR}=.063$; RMSEA $=.097 \mathrm{]}$ şeklinde olduğu görülmektedir. Doğrulayıcı faktör analizi sonuçlarının kriterleri karşılayıp karşılamadığına ilişkin bulgular Tablo 1'de sunulmuştur.

Tablo 1.Milwaukee Psikoterapi Beklentileri Ölçeği'ne İlişkin Doğrulayıcı Faktör Analizi Sonuçlarn

\begin{tabular}{llll}
\hline Uyum indeksi & Hesaplanan Değer & Kabul Edilebilir Değerler & Sonuç \\
\hline$\chi^{2} / \mathrm{sd}$ & 4.08 & $\chi^{2} / \mathrm{sd} \leq 5.00$ & Kabul \\
GFI & .90 & $\mathrm{GFI} \geq .90$ & Kabul \\
CFI & .90 & $\mathrm{CFI} \geq .90$ & Kabul \\
IFI & .91 & $\mathrm{CFI} \geq .90$ & Kabul \\
SRMR & .063 & SRMR $\leq .08$ & Kabul \\
RMSEA & .097 & RMSEA $\leq .10$ & Kabul $^{*}$ \\
\hline
\end{tabular}

*RMSEA uyum indeksi, düşük bir değere sahip olmasına rağmen, diğer uyum indekslerinin yeterli olmasından dolayı kabul edilmiştir.

Not. Kabul edilebilir değerler için Bollen, 1989, Hooper, Coughlan ve Mullen, 2008, Hu ve Bentler, 1999, Joreskog ve Sorbom 1993 ile Stevens, J.P. 2001'ın önerileri dikkate alınmıştır. 


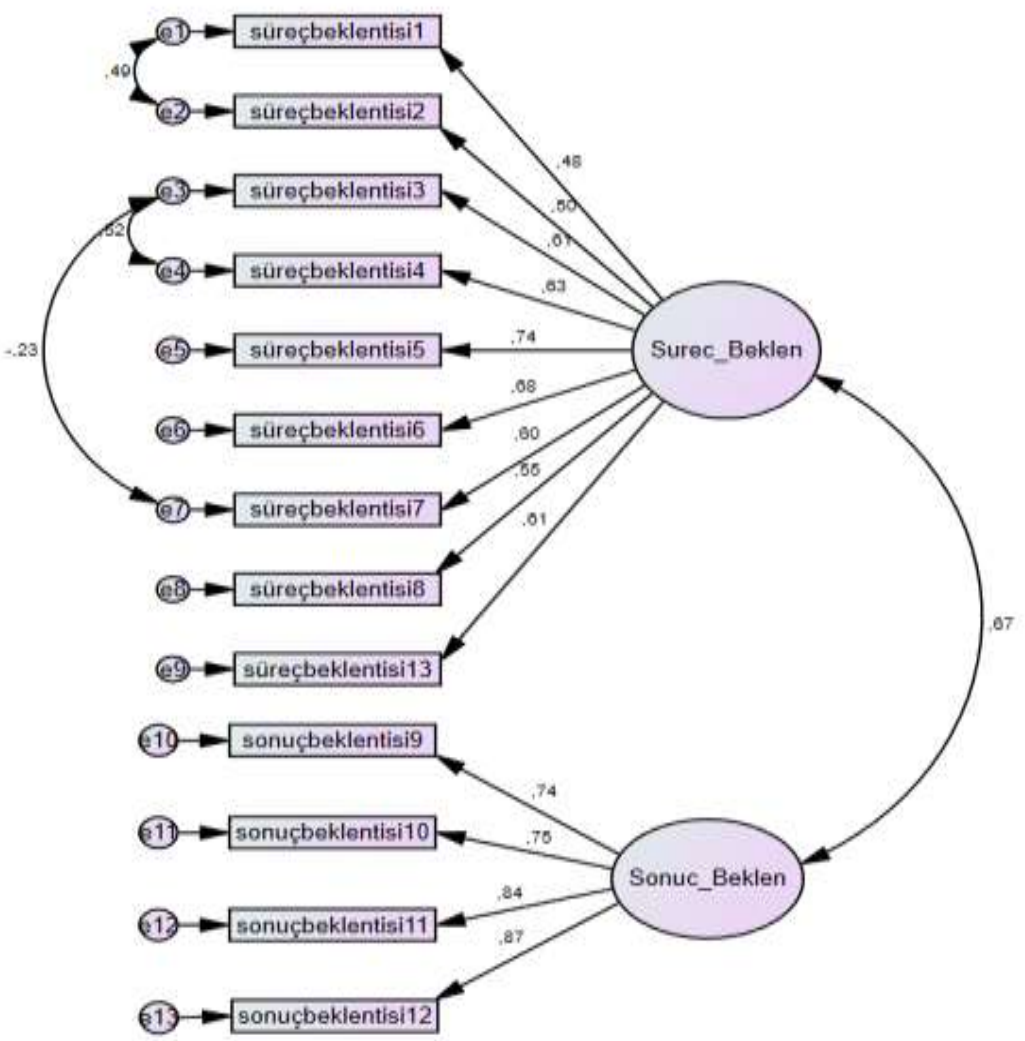

Şekil 1. MPBÖ’ nün DFA sonuçları

Uyum Geçerliği:Milwaukee Psikoterapi Beklentileri Ölçeği'nin uyum geçerliğini sınamak amacıyla Psikolojik Yardım Almaya İlişkin Tutum Ölçeği-Kısa Formu (PYAİTÖ-KF) ve Psikoterapi Hakkında Düşünceler Ölçeği (PHDÖ) ile arasındaki ilişkiler değerlendirilmiştir. Bu kapsamda MPBÖ'nün alt boyutları olan süreç ve sonuç beklentileri, PYAİTÖ-KF toplam puanı olan psikolojik yardım almaya ilişki tutum ve PHDÖ'nün alt boyutları olan terapist tepkisi, imaj sorunu ve zorlanma sorunu ile ilişkileri analize dahil edilmiştir. Uyum geçerliğine yönelik sonuçlar Tablo 2 'de sunulmuştur. 
Tablo 2. Milwaukee Psikoterapi Beklentileri Ölçeği'ne ait Uyum Geçerliği Sonuçları

\begin{tabular}{lllll}
\hline Değişken & PYAİTÖ-KF & Terapist tepkisi & İmaj sorunu & $\begin{array}{l}\text { Zorlanma } \\
\text { sorunu }\end{array}$ \\
\hline Süreç Beklentileri & $.309^{* *}$ & -.086 & $-.139^{*}$ & $-.129^{*}$ \\
Sonuç Beklentileri & $.381^{* *}$ & -.096 & -.025 & -.065 \\
\hline Not. ${ }^{* *} p<.01,{ }^{*} p<.001 ;$ PYAİTÖ-KF Psikolojik Yardım Almaya İlişkin Tutum Ölçeği-Kısa & Als \\
Formu
\end{tabular}

Tablo 2'de görüldüğü üzere, süreç beklentileri psikolojik yardım almaya yönelik tutum ile pozitif yönde anlamlı ilişkilidir, $(r=.309, p<$ .001). Diğer taraftan, süreç beklentileri; imaj sorunu $(r=-.139, p<.01)$ ve zorlanma sorunu $(r=-.129, p<.01)$ ile negatif yönde anlamlı ilişkilidir. Ancak, süreç beklentilerinin terapist tepkisi ile anlamlı ilişki göstermediği belirlenmiştir, $(r=-.086, p>.05)$.

Sonuç beklentileri boyutunun da psikolojik yardım almaya yönelik tutum ile pozitif yönde anlamlı ilişkili olduğu görülmüştür, $(r=.381, p<$ .001). Ancak, sonuç beklentilerinin terapist tepkisi $(r=-.096, p>.05)$, imaj sorunu $(r=-.025, p>.05)$ ve zorlanma sorunu $(r=-.065, p>.05)$ ile ise anlamlı bir ilişkiye sahip olmadığı saptanmıştır. Psikoterapi Hakkında Düşünceler Ölçeği ile sonuç beklentileri alt boyutunun anlamlı ilişkilerinin olmaması, PHDÖ'nün terapi esnasına odaklanması fakat MPBÖ'nün sonuç beklentileri alt boyutunun terapinin sonucu ile ilgili olmasıyla açıklanabilinir.

Modelin RMSEA değerine baktığımızda, RMSEA değerinin $0.05^{\prime} \mathrm{e}$ eşit ya da altında olması iyi uyum, 0.05 ile 0.08 arasında olması yeterli uyum, 0.08 ile 0.10 arasında olması kabul edilebilir uyum, 0.10 'dan büyük olması ise kabul edilemez uyum olarak gösterilmektedir (Kaplan,2000; Kline, 2011; Erkorkmaz, Etikan, Demir, Özdamar ve Sanisoğlu, 2013). Modelin RMSEA indeksinin üst sınır olan 0.10 a yaklaşması, indeksin her ne kadar kabul edilebilir sınırlar içerisinde olsa da kötü bir uyuma yaklaştığını göstermektedir. Bununla birlikte, alanyazın irdelendiğinde RMSEA indeksinin aldıkları değerlerin örneklem büyüklüğünden etkilenebildikleri (Şimşek, 2007) belirtilmektedir. Örneklemden etkilenmeyen uyum iyiliği indekslerinin incelenmesinin daha sağlıklı sonuçlar verebileceği düşünülmüş, bu amaçla CFI ve IFI değerlerine bakılmıştır. Bu indeksler için .90 seviyesi ve üzerinde değerler modelin kabul edilebilir olduğunu göstermektedirler (Şimşek, 2007). Sonuç olarak yapı geçerliği bağlamında 
her ne kadar RMSEA indeksinin belirtilen yeterli uyum değerleri içerisinde olmasa da diğer uyum iyiliği indeksleri ve faktör yüklerinin anlamlı olması nedeniyle yapı geçerliğinin sağlandığı ifade edilebilir. Ayrıca uyum geçerliği olarak da psikolojik yardım almaya yönelik tutum ile saptanan pozitif yöndeki anlamlı ilişki ve süreç beklentileri alt boyutunun psikoterapi hakkındaki düşünceler ölçeğinin imaj sorunu ve zorlanma sorunu ile anlamlı ilişkiye sahip olması uyum geçerliği için yeterli olmaktadir.

\section{Güvenirlik}

Milwaukee Psikoterapi Beklentileri Ölçeği'nin güvenirliğini belirleyebilmek için Cronbach Alfa ile test-tekrar test güvenirlik katsayıları hesaplanmış ve madde-analizi gerçekleştirilmiştir. Bu doğrultuda Cronbach alfa ile test-tekrar test güvenirlik katsayılarına ilişkin sonuçlar Tablo 3'de sunulmuştur. Ek olarak, Tablo 1'de MPBÖ'nün maddelerine ait düzeltilmiş madde-toplam korelasyonları da yer verilmiştir.

Tablo 3. Milwaukee Psikoterapi Beklentileri Ölçeği'ne ait Güvenirlik Sonuçları

\begin{tabular}{lllllll}
\hline Boyut & Madde No & $\boldsymbol{r}_{j x}$ & $\mathbf{M}$ & ss & $\boldsymbol{\alpha}$ & test-tekrar test \\
\hline & 1 & .49 & 8.11 & 2.22 & & \\
& 2 & .54 & 8.35 & 1.90 & & \\
& 3 & .56 & 8.28 & 2.06 & & \\
Süreç Beklentileri & 4 & .62 & 8.31 & 2.04 & & \multirow{6}{*}{} \\
& 5 & .67 & 8.74 & 1.78 & .84 & .82 \\
& 6 & .59 & 8.10 & 2.32 & & \\
& 7 & .46 & 7.60 & 2.36 & & \\
& 8 & .46 & 8.19 & 2.17 & & \\
Sonuç Beklentileri & 13 & .55 & 8.47 & 1.83 & & \\
& 9 & .70 & 7.96 & 2.41 & & .76 \\
& 10 & .71 & 7.99 & 2.07 & \multirow{2}{*}{.88} & \\
\hline
\end{tabular}

Tablo 3'den anlaşılacağı üzere, Milwaukee Psikoterapi Beklentileri Ölçeği'nin hem süreç beklentisi $(\alpha=.84)$ hem de sonuç beklentisi $(\alpha=.88)$ boyutlarının Cronbach alfa katsayılarının kabul edilebilir düzeyde olduğu 
anlaşılmaktadır. Benzer şekilde test tekrar test güvenirlik katsayısı açısından da her iki boyutunda yeterli güvenirlik katsayısına sahip olduğu ifade edilebilir (Süreç alt boyutu, .82 ve Sonuç alt boyutu .76).

Milwaukee Psikoterapi Beklentileri Ölçeği'nin madde analizi bulgularına göre düzeltilmiş madde-test korelasyonlarının süreç beklentileri boyutunda (.46 ile .67) ve sonuç beklentileri boyutunda (.70 ile .78) arasında değiştiği, regresyon analizine göre varsayımlar test edilmiş ve sağlandıkları görülmüştür. Maddelerin, ölçülmek istenilen boyut açısından bireyleri iyi derecede ayırt ettiği söylenebilir. Tüm bu güvenirlik analizleri sonucunda Milwaukee Psikoterapi Beklentileri Ölçeğinin yeterli güvenirliğe sahip olduğu vurgulanabilir.

\section{Tartışma}

Milwaukee Psikoterapi Beklentileri Ölçeği'nin (MPBÖ) yapı geçerliğini s1namak amacıyla yapılan doğrulayıcı faktör analizi' nin ilk sonuçlarına göre Milwaukee Psikoterapi Beklentileri Ölçeği'nin uyum iyiliği indekslerinin kritik değerin altında olduğu anlaşılmıştır. Bununla birlikte, süreç boyutunun 1 ve 2 nolu, 3 ve 4 nolu ile 3 ve 7 nolu maddeleri arasinda modifikasyon indekslerinin oldukça yüksek olduğu görülmüştür. Bu bağlamda bu maddeler arasında modifakasyon yapılarak DFA yenilenmiştir. Modifikasyon yapılarak yenilenen DFA sonucunda, ölçeğin uyum iyiliği indekslerinin kabul edilebilir değerlerde görülmektedir.

Yapılan modifikasyon, modelin teorik yapısına uygun bir şekilde kurulmuştur. Aynı alt boyutta ve amaç olarak birbirlerine benzeyen maddeler arasında gerçekleştirilmiştir. 1 nolu madde "Terapistimin bana destek vermesini beklerim", 2 nolu madde "Terapistim bana geri bildirim verecektir" şeklindedir. Her iki madde de süreç beklentileri alt boyutunda yer almakta, süreç beklentilerinin rol beklentileri türündedir. Bu iki maddede terapistin nasıl bir davranış sergileyeceği yani nasıl bir rol göstereceği ile ilgili beklentiyi ölçmektedir. Bu nedenle bu iki madde arasında yapılan modifikasyon, modele ve kuramsal alt yapıya uygundur. 3 nolu madde "Terapide gerçek düşünce ve hislerimi ifade edebileceğim" ve 4 nolu madde "Terapistimleyken kendimi rahat hissedeceğim" şeklindedir. Bu iki madde de 1 ve 2 nolu maddeler gibi süreç beklentisi alt boyutuna ait ve süreç beklentilerinin rol beklentileri türündendir. Fakat 1 ve 2 nolu 
maddelerden farkı, 1 ve 2 nolu maddelerin terapist rolü ile ilgiliyken, 3 ve 4 nolu maddelerin danışan rolü ile ilgili olmasıdır. Böylelikle bu iki madde arasında yapilan modifikasyon da modele ve kuramsal yapiya uygundur. 3 nolu maddeyle yapılan ikinci modifikasyon, 7 . Nolu madde ile yapılmıştır. 7 nolu madde "Terapistim sempatik olacaktır" şeklindedir. Bu iki madde de süreç beklentisi alt boyutunda ve rol beklentisi türündedir. Fakat maddelerden biri terapist rolüne aitken, diğeri danışan rolü ile ilgilidir. Bu noktadan bakıldığında, terapistin sempatik olması ile danışanın gerçek düşünce ve hislerini ifade etmesi arasında dolaylı bir ilişki olduğu düşünülebilir. Bu modifikasyonunda hem model hem de kuramsal olarak uygun olduğu söylenebilir.

MPBÖ'nün uyum geçerliğine bakıldığında süreç beklentileri psikolojik yardım almaya yönelik tutum ile pozitif yönde anlamlı ilişkilidir, $(r=.309$, $p<.001)$. Diğer taraftan, süreç beklentileri; imaj sorunu $(r=-.139, p<.01)$ ve zorlanma sorunu $(r=-.129, p<.01)$ ile ise negatif yönde anlamlı ilişkilidir. Ancak, süreç beklentilerinin terapist tepkisi ile anlamlı ilişki göstermediği belirlenmiştir, $(r=-.086, p>.05)$.

Sonuç beklentileri boyutunun da psikolojik yardım almaya yönelik tutum ile pozitif yönde anlamlı ilişkili olduğu görülmüştür, $(r=.381, p<$ .001). Ancak, sonuç beklentilerinin terapist tepkisi $(r=-.096, p>.05)$, imaj sorunu $(r=-.025, p>.05)$ ve zorlanma sorunu $(r=-.065, p>.05)$ ile ise anlamlı ilişkili olmadığı saptanmıştır. MPBÖ'nün PYAİTÖ-KF ile uyumuna bakıldığında, MPBÖ'nün her iki alt boyutununda PYAİTÖ-KF ile anlamlı bir ilişkisi olduğu görülmüştür. Teorik açıdan, beklentiyle tutum arasındaki anlamlı ilişkiyi araştırmacılar sık sık değinmişlerdir. Buradaki sonuçlarda psikoterapi beklentileri ile yardım alma tutumunun doğru orantılı olduğunu göstermektedir.

MPBÖ'nün PHDÖ ile uyumlarına bakıldığında, MPBÖ'nün sonuç beklentileri alt boyutu ile PHDÖ'nün alt boyutları arasında anlamlı ilişki olmaması, PHDÖ'nün bireylerin yardım almadan önce ya da yardım alma sırasındaki korkuları ölçmesiyle ilgili olduğu düşünülmektedir. PHDÖ sürecin başlangıcındaki ve sürecin içerisindeki verileri ölçmeye yönelik geliştirildiği için, sürecin sonucuyla ilgili bilgileri ölçen sonuç beklentileriyle anlamlı ilişkisinin olmaması beklenen bir sonuçtur. Bu bakış açısıyla bakıldığında, MPBÖ'nün süreç beklentileri alt boyutunun PHDÖ'nün alt boyutlarıyla anlamlı ilişki taşıması beklenebilir. Sonuçlara bakıldığında, 
süreç beklentilerinin, imaj sorunu ve zorlanma sorunu ile negatif yönde anlamlı olduğu fakat terapist tepkisi ile herhangi bir anlamlı ilişki göstermediği görülmektedir. Bu noktada süreç beklentisinin, imaj sorunu ve zorlanma sorunu ile anlamlı ilişki göstermesine rağmen terapist tepkisi ile anlamlı bir ilişki göstermemesi düşündürücüdür.

Sonuç olarak yapı geçerliği bağlamında her ne kadar RMSEA indeksinin belirtilen değerler içerisinde olmasa da diğer uyum iyiliği indeksleri ve faktör yüklerinin anlamlı olması nedeniyle yapı geçerliğinin sağlandığı ifade edilebilir. Ayrıca uyum geçerliği olarak da psikolojik yardım almaya yönelik tutum ile saptanan pozitif yöndeki anlamlı ilişki uyum geçerliği için yeterli olmakla birlikte PHDÖ ile anlamsız ilişkiler düşündürücü bulunmuştur.

MPBÖ'nün güvenirliğini belirleyebilmek için Cronbach Alfa ile testtekrar test güvenirlik katsayıları hesaplanmış ve madde-analizi gerçekleştirilmiştir. Milwaukee Psikoterapi Beklentileri Ölçeği'nin hem süreç beklentisi $(\alpha=.84)$ hem de sonuç beklentisi $(\alpha=.88)$ boyutlarının Cronbach alfa katsayılarının kabul edilebilir düzeyde olduğu anlaşılmaktadır. Benzer şekilde test-tekrar test güvenirlik katsayısı açısından da her iki boyutunda yeterli güvenirlik katsayısına sahip olduğu ifade edilebilir (sırasiyla, .82 ve .76$)$.

\section{Sonuç}

Sonuç olarak, Milwaukee Psikoterapi Beklentileri Ölçeği'nin geliştirildiği kültürdeki orijinal formu gibi 13 maddeden, süreç beklentileri ve sonuç beklentileri şeklinde 2 alt boyuttan oluştuğu ortaya konmuştur. Ölçek 0 ile 10 arasinda puanlanmakta ve alt boyutlara ait olan maddelere verilen puanlara göre değerlendirilmektedir. Psikoterapiye yönelik beklentileri ölçmek için geliştirilmiş bu ölçek, yurtdışında farklı çalışmalarda kullanılmıştır. Geçerliği ve güvenirliği ispatlanmış bu ölçeği Türk kültürüne kazandırmak, alanda yapılacak diğer psikoterapi ile ilgili ölçek çalışmalarına katkı sağlayacaktır. Ayrıca bu ölçeğin kullanımı ile psikoterapi hizmetlerinin dinamiğine etki eden bir çok faktörün inceleneceği çalışmalar yapılarak psikolojik yardım ve psikoterapi alanına katkı sağlayacağı düşünülmektedir. 


\section{EXTENDED ABSTRACT}

\section{Adaptation of Milwaukee Psychotherapy Expectations Scale into Turkish: Validity and Reliability Study \\ *}

Kerem Çetinkaya - Çiğdem Yavuz Güler

National Defence University, Üsküdar University

Psychotherapy researchs indicate that the expectations of the clients regarding psychotherapy are important in the treatment process. (Constantino, 2012; Frank, 1968, 1973; Goldstein, 1962; Goldstein and Shipman, 1961; Gonzalez, Tinsley and Kreuder, 2002; Grencavage and Norcross, 1990; Rosenthal and Frank, 1956). The researchers state that the expectations of the clients affect the initiation of psychotherapy, the process and the outcome of the psychotherapy (Volpe, 2014). People come with some expectations of how and how much help they can get from psychotherapy (Frank, 1968; Goldstein, Heller and Sechrest, 1966; Greenberg, Constantino and Bruce, 2006; Norberg, Wetterneck, Sass and Kanter, 2011; Tinsley and Harris, 1976). These expectations are important factors that affect the behavior of the client during the counseling process such as the initiation of psychotherapy or the willingness to share specific information about themselves in the process (Tinsley, Workman and Kass, 1980). These studies demostrate that client's expectations affect the process of psychotherapy; psychotherapeutic interventions, the behavior of the client and the efficiency of therapy.

The concept of expectation has been one of the focus concepts of psychology and psychological researches (Tinsley, Bowman and Barich, 1993). Researchers consider clients' expectations as an effective element of the therapy process and outcome of the therapy (Tinsley, Brown, Aubin, and Lucek, 1984). Different researchers designed different expectation dimensions (Berzins, 1971). Therapy expectation is generally described in the literature as treatment expectations and outcome expectations (Tinsley, Holt, Hinson and Tinsley, 1991). During literature review on the concept of expectation, it was realized that expectations for psychotherapy 
were not studied much in Turkey. When the measurement tools related to the expectation of psychotherapy were examined, it was found that the same deficiency was also seen here. In this study, it was aimed to adapt the Milwaukee Psychotherapy Expectations Questionnaire (MPEQ) to Turkish culture, which was developed by Norberg, Wetterneck, Sass and Kanter (2011), and to evaluate the validity and reliability of the scale.

While the validity and reliability studies of the Milwaukee Psychotherapy Expectations Questionnaire were conducted, all participants were selected from adult individuals. The participants of the study consisted of 328 individuals (248 females, 80 males). To collect data in the study, besides the MPEQ, the Scale of Attitude Towards Psychological AssistanceShort Form and the Thoughts on Psychotherapy Scale were used to test the convergent validity.

Milwaukee Psychotherapy Expectations Questionnaire - MPEQ developed by Norberg et al. (2011), which measures the expectations of individuals for psychotherapy, consists of 13 items, has two dimensions as process expectations and outcome expectations, evaluated between 0 (None) and 10 (Too Much), is a data collection tool whose validity and reliability were proved. Confirmatory factor analysis (CFA) was perfomed to test the construct validity of the Milwaukee Psychotherapy Expectations Questionnaire (MPEQ). According to the preliminary results of the CFA, all indexes were found to be below the critical value $[\chi 2(64, \mathrm{~N}=328)=456.312$, $\chi 2$ / $\mathrm{sd}=7.13 ; \mathrm{GFI}=.82 ; \mathrm{CFI}=.80$; IFI = .80; $\mathrm{SRMR}=.083$; $\mathrm{RMSEA}=.137]$ However, it has been found that the modification indices of the process subscale between 1and 2, 3 and 4, 3 and 7 are quite high. In this manner, CFA was regenerated by modifying the relation between these items.

As a result of the renewed CFA, it was understood that the standardized factor loads of the scale ranged between .48 and .74 and all factor loads are significant. Similarly, it was found that standardized factor loadings ranged between .74 and .87 and all factor loads were significant in terms of outcome expectations. Goodness of fit indices of the scale are indicated as $[\chi 2(61, \mathrm{~N}=328)=249.315, \chi 2 / \mathrm{sd}=4.08 ; \mathrm{GFI}=.90 ; \mathrm{CFI}=.90 ; \mathrm{IFI}$ $=.91 ;$ SRMR $=.063 ;$ RMSEA $=.097]$.

To provide additional evidence for the validity of the MPEQ, correlational analyses were conducted to test for the associations between each 
of the subscales. Process expectations were positively correlated with attitudes towards receiving psychological help, $(\mathrm{r}=.309, \mathrm{p}<.001)$. On the other hand, process expectations were negatively correlated with image concerns $(\mathrm{r}=-.139, \mathrm{p}<.01)$ and coercion concerns $(\mathrm{r}=-.129, \mathrm{p}<.01)$. However, it was determined that process expectations did not show a significant relationship with therapist response $(r=-.086, p>.05)$. It was also found that the result expectations dimension was positively correlated with the attitude towards receiving psychological help $(\mathrm{r}=.381, \mathrm{p}<.001)$. However, there was no significant relationship between outcome expectations and therapist's response $(r=-.096, p>.05)$, image problem $(r=-.025$, $\mathrm{p}>.05)$ and strain problem $(\mathrm{r}=-.065, \mathrm{p}>.05)$. The fact that there is no relation between the "Thoughts About Psychotherapy Scale" and "result expectancy sub-dimension" can be explained as while TAPS is concentrating on the therapy session "MPEQ result expectancy sub-dimension" is related with the output of the therapy.

In order to determine the reliability of the Milwaukee Psychotherapy Expectations Questionnaire, test-retest reliability coefficients were calculated with Cronbach Alpha and item-analysis was performed. The Cronbach alpha coefficients of the Milwaukee Psychotherapy Expectations Questionnaire were both acceptable in terms of process expectation $(\alpha=.84)$ and outcome expectation $(\alpha=.88)$. Similarly, it can be stated that it has sufficient reliability coefficient in both dimensions in terms of testretest reliability coefficient (Process sub-dimension, .82 and Result sub-dimension .76). It was found that item-test correlations were adjusted according to the item analysis findings of the scale between process expectations dimension (.46 and .67) and result expectations dimension (.70 to .78). It can be said that the items distinguish the individuals well in terms of the dimension to be measured. As a result of all these reliability analyzes, it can be emphasized that Milwaukee Psychotherapy Expectations Questionnaire has sufficient reliability.

As a result, it was revealed that the Milwaukee Psychotherapy Expectations Questionnaire consisted of 13 items like the original form and two sub-dimensions as process expectations and outcome expectations. The scale is scored between 0 and 10 and evaluated according to the scores given to the items belonging to the sub-dimensions. The adaptation of the scale, having been confirmed with validity and reliability tests, to Turkish 
Culture will contribute to the other studies in psychotherapy and related scale studies. Moreover, utilization of the scale will support the studies investigating the factors having effect on the dynamics of psychotherapy services. It is considered, with respect, that such studies will make a contribution to the field of psychological help and psychotherapy.

\section{Kaynakça / References}

Berzins, J. E. (1971). Revision of the psychotherapy expectancy inventory, Unpublished manuscript.

Bollen, K.A. (1990). Overall fit in covariance structure models: Two types of sample size effects, Psychological Bulletin, 107 (2), 256-59.

Connolly Gibbons, M. B., Crits-Christoph, P., de la Cruz, C., Barber, J. P., Siqueland, L. ve Gladis, M. (2003). Pretreatment expectations, interpersonal functioning, and symptoms in the prediction of the therapeutic alliance across supportive-expressive psychotherapy and cognitive therapy. Psychotherapy Research, 13(1), 59-76, doi: 10.1093/ptr/kpg007

Constantino, M. J (2012) Believing is seeing: An evolving research program on patients' psychotherapy expectations. Psychotherapy Research, 22(2), 127-138, doi: 10.1080/10503307.2012.663512

Constantino, M. J., Glass, C. R., Arnkoff, D. B., Ametrano, R. M. ve Smith, J. Z. (2011). Expectations. In (J. C. Norcross, Ed.), Psychotherapy relationships that work: Evidence-based responsiveness, 354-376. New York, NY: Oxford University Press.

Constantino, M, J., Ametrano, R. M. ve Greenberg, R. P. (2012). Clinician intervention and participant characteristics that foster adaptive patient expectations for psychotherapy and psychotherapeutic change. Psychotherapy, 49, 557-569. doi:10.1031/a0029440

Dew, S. E. ve Bickman, L. (2005). Client expectancies about therapy, Mental Health Services Research, 7, 21-33. doi:10.1007/s11020-005-1963-5

Ekberg, S., Barnes, R.K., Kessler, D.S., Malpass, A. ve Shaw, A.R.G. (2014) Relationship between expectation management and client retention in online Cognitive Behavioural Therapy. Behavioural and Cognitive Psychotherapy, doi:10.1017/S1352465814000241.

Erkorkmaz, Ü., Etikan, İ., Demir, O., Özdamar, K. ve Sanisoğlu, S. Y. (2013). Doğrulayıc faktör analizi ve uyum indeksleri. Türkiye Klinikleri Tıp Bilimleri Dergisi, 33(1), 210-223. 
Fischer, E. H. ve Turner, J. L. (1970). Orientations to seeking professional help: development and research utility of an attitude scale erratum, Journal of Consulting and Clinical Psychology, 35(3). Doi: 10.1037/h0020198.

Fischer, E. H. ve Farina, A. (1995). Attitudes toward seeking Professional psychological help: A shortened form and considerations for research. Journal of College Student Development, 36, 368-373.

Frank, J. D. (1958). Some effects of expectancy and influence in psychotherapy, In ( J. H. Masserman, ve J. L. Moreno Eds.), Progress in psychotherapy, (vol. 3.) (p. 21-43). New York7 Grune and Stratton

Frank, J. D. (1961). Persuasion and healing. Baltimore, MD: Johns Hopkins University Press.

Frank, J. D. (1968). The influence of patients' and therapists' expectations on the outcome of psychotherapy, British Journal of Medical Psychology, 41, 349-356.

Garfield, S. L. (1994). Research on client variables in psychotherapy, In (A. E. Bergin, and S. L. Garfield Eds.), Handbook of psychotherapy and behavior change, (4th ed.). New York: Wiley.

Glass, C. R., Arnkoff, D. B. ve Shapiro, S. J. (2001). Expectations and preferences. Psychotherapy, 38, 455-461. doi:10.1037/0033-3204.38.4.455

Goldstein, A. P. (1962). Therapist-patient expectancies in psychotherapy. New York: Pergamon Press.

Gonzalez, J. M., Tinsley, H. E. A. ve Kreuder, K. R. (2002). Effects of psychoeducational interventions on opinions of mental illness, attitudes toward help seeking, and expectations about psychotherapy in college students. Journal of College Student Development, 43(1), 51-63.

Greenberg, R. P., Constantino, M. J. ve Bruce, N. (2006). Are patient expectations still relevant for psychotherapy process and outcome?. Clinical psychology review, 26(6), 657-678.

Grencavage, L.M. ve Norcross, J.C. (1990). Where are the commonalities among the therapeutic common factors? Professional Psychology: Research and Practice, 21, 372-378. doi:10.1037/0735-7028.21.5.372

Heilbrun, A.B. (1972). Effects of briefing upon client satisfaction with the initial counseling contact. Journal of Consulting and Clinical Psychology, 38, 50-56.

Kaplan, D. (2000). Structural equation modeling: foundations and extensions advanced quantitative techniques in the social sciences. USA: Sage Publications, Inc. 
Kline, B.R. (2011). Principles and practice of structural modeling (3. bs.). New York-London: The Guilford Press.

Kushner, M. G. ve Sher, K. J. (1989). Fears of psychological treatment and its relation to mental health service avoidance. Professional Psychology: Research and Practice, 20, 251-257.

Lambert, M. J. ve Barley, D. E. (2001). Research summary on the therapeutic relationship and psychotherapy outcome. Psychotherapy: Theory, Research, Practice, Training, 38(4), 357-361. doi:10.1037/0033-3204.38.4.357

Norberg, M. M., Wetterneck, C. T., Sass, D. A. ve Kanter, J. W. (2011). Development and psychometric evaluation of the Milwaukee Psychotherapy Expectations Questionnaire. Journal of Clinical Psychology, 67(6), 574-590. doi:10.1002/jclp.20781

Sousa, V. ve Rojjanasrirat W. (2011). Translation, adaptation and validation of instruments or scales for use in cross-cultural health care research: A clear and user-friendly guideline. Journal of Evaluation in Clinical Practice, 17, 268-274.

Şimşek, Ö. F. (2007). Yapısal eşitlik modellemesine giriş temel ilkeler ve lisrel uygulamaları. Ankara: Ekinox

Tambling, R. B., Wong, A.G. ve Anderson, S. R. (2014). Client expectations about couple therapy. The American Journal of Family Therapy, 42(4), 29-41.

Tinsley, H. E. ve Harris, D. J. (1976). Client expectations for counseling. Journal of Counseling Psychology, 23(3), 173-177. doi: 10.1037/00220167.23.3.173

Tinsley, H. E. A., Workman, K. R. ve Kass, R. A. (1980). Factor analysis of the domain of client expectancies about counseling. Journal of Counseling Psychology, 27, 561-570.

Tinsley, H. E., Brown, M. T., de St. Aubin, T. ve Lucek, J. (1984). Relationship between expectancies for a helping relationship and tendency to seek help from a campus help provider. Journal of Counseling Psychology, 31(2), 149-160. doi: 10.1037/0022- 0167.31.2.149

Tinsley, D. J., Holt, M. S., Hinson, J. A. ve Tinsley, H. E. A. (1991). Aconstruct validation study of the Expectations About Counseling Brief Form: Factorial validity. Measurement and Evaluation in Counselingand Development, 24(3), 101-110. 
Tinsley, H. E. A., Bowman, S. L. ve Barich, A. W. (1993). Counselingpsychologists' perceptions of the occurrence and effects of unrealisticexpectations about counseling and psychotherapy among their clients. Journal of Counseling Psychology, 40(1), 46-52.

Topkaya, N. (2011). Psikolojik yardım alma niyetinin sosyal damgalanma, tedavi korkusu, beklenen yarar, beklenen risk ve tutum faktörleriyle modellenmesi. Yayınlanmamış Doktora Tezi. İzmir: Ege Üniversitesi.

Volpe E. G. (2014). Belief in the efficacy of psychotherapy (BEP): Psychometric scale development and examination of theoretical correlates. University of Tennessee - Knoxville.

Wierzbicki, M. ve Pekarik, G. (1993). A meta-analysis of psychotherapy dropout. Professional Psychology: Research \& Practice, 24, 190-195.

\section{EK-1 Milwauke Psikoterapi Beklentileri Ölçeği}

Aşağıda, psikoterapi ile ilgili olası beklentilerinizi açıklayan ifadeler listelenmiştir. Bu ifadeler terapideki davranışlarınızı, gelecekteki terapistinizi ve terapi süreci ile ilgili beklentilerinizi kapsamaktadır. Daha önce bir psikoterapi deneyiminiz olmayabilir veya olası beklentileri daha önce düşünmemiş olabilirsiniz lakin şimdi bunlarla alakalı düşünmenizi istiyoruz. Her bir ifadeyi dikkatlice okuyup, ifade edilen durumla ilgili ne düzeyde beklenti içerisinde olduğunuzu gösteren rakamı yuvarlak içine alınız.

\begin{tabular}{|c|c|}
\hline & $\begin{array}{ll}\text { Biraz } & \text { Çok fazla } \\
\end{array}$ \\
\hline 1. Terapistimin bana destek vermesini beklerim. & 0122334566789910 \\
\hline 2. Terapistim bana geri bildirim verecektir. & 0122334566789910 \\
\hline 3. Terapide gerçek düşünce ve hislerimi ifade edebileceğim. & 0112334566789910 \\
\hline 4. Terapistimleyken kendimi rahat hissedeceğim. & 0122345678910 \\
\hline 5. Terapistim samimi/içten olacaktır. & 0122334566789910 \\
\hline 6. Terapistim söyleyeceğim şeylere ilgi duyacaktır. & 0112334556789910 \\
\hline 7. Terapistim sempatik olacaktır. & 0122334566789910 \\
\hline 8. Her terapi randevuma gideceğimi düşünüyorum. & 0112334566789910 \\
\hline 9. Terapi kendime olan saygımın artmasını sağlayacaktır. & $0 \begin{array}{llllllllll}0 & 1 & 2 & 3 & 4 & 5 & 6 & 78 & 9 & 10\end{array}$ \\
\hline $\begin{array}{l}\text { 10. Terapiden sonra, gelecekte yaşayabileceğim sıkıntılı } \\
\text { hislerden kaçınmak için gerekli güce sahip olacağım. }\end{array}$ & 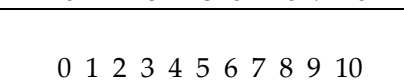 \\
\hline 11. Terapi neticesinde daha iyi bir insan olmayı umuyorum. & 01223455678910 \\
\hline 12. Terapiden sonra çok daha iyimser olacağım. & 0112334566789910 \\
\hline $\begin{array}{l}\text { 13. Terapi ile alakalı endişelerim olduğunda bunu } \\
\text { terapistime söyleyeceğimi düşünüyorum. }\end{array}$ & 01223456678910 \\
\hline $\begin{array}{l}\text { Puanlama: Milwauke Psikoterapi Beklentileri Ölçeği için pua } \\
\text { temi aşağıdaki gibidir. } \\
\text { Süreç Beklentileri Puanı 1-2-3-4-5-6-7-8 ve13. maddelerden a } \\
\text { Sonuç Beklentileri Puanı, 9-10-11 ve 12. maddelerden alınan } \\
\text { maktadır. }\end{array}$ & $\begin{array}{l}\text { anlama ve değerlendirme sis- } \\
\text { lınan puanların toplanmasıyla, } \\
\text { puanların toplanmasıyla oluş- }\end{array}$ \\
\hline
\end{tabular}


Milwaukee Psikoterapi Beklentileri Ölçeğinin Türkçeye Uyarlanması: Geçerlik ve Güvenirlik Çalışması

Değerlendirme: Süreç ve Sonuç beklentileri boyutları için ayrı ayrı toplam puan alınabilmektedir. Alınan puanın yükseliği kişinin psikoterapiye yönelik beklentisinin yüksekliğine işaret etmektedir.

\section{Kaynakça Bilgisi / Citation Information}

Çetinkaya, K. ve Yavuz Güler, Ç. (2020). Milwaukee psikoterapi beklentileri ölçeğinin Türkçeye uyarlanması: Geçerlik ve güvenirlik çalışması. OPUS-Uluslararası Toplum Araştırmaları Dergisi, 15(21), 257281. DOI: 10.26466/opus.595768 